\title{
Examination of the Hexad User Types and their Relationships with Gender, Game Mode, and Gamification Experience in the Context of Open and Distance Learning
}

\author{
Dilek Şenocak \\ Anadolu University, Eskişehir, Turkey \\ Köksal Büyük \\ Anadolu University, Eskişehir, Turkey \\ Aras Bozkurt \\ Anadolu University, Eskişehir, Turkey \\ University of South Africa, Pretoria, South Africa
}

\begin{abstract}
Gamification, which is defined as the use of game design elements in non-game contexts, is put forward as a solution to low motivation and is suggested for the creation of a sustainable learning ecology in open and distance learning (ODL). The overall purpose of the present study was to examine the distribution of the Hexad gamification user types and the correlations of gamification experience, game mode, and gender with the user types' scores within the context of an ODL system. The researchers adapted quantitative cross-sectional survey design to seek answers in this study. The Hexad user types of distance learners were determined based on the online "Gamification User Types Hexad Scale." Findings revealed that the most common user types in the ODL environment were Philanthropists, Achievers, and Free Spirits, followed by Socializers and Players with a lower mean, while the least common user type was Disruptors. Women tended to score higher than men on the Disruptor user type. Achievers, Socializers, Philanthropists, and Players preferred multiplayer game modes, while the game mode had little influence on Free Spirits and Disruptors. Regarding the gamification experience, Players and Free Spirits seemed to have more experience of gamified applications. This study provides insights to learning designers in developing gamified ODL systems to engage the different Hexad user types.
\end{abstract}

Keywords: distance education, gamification, the Hexad user types, game mode, gamification experience

Şenocak, D., Büyük, K., \& Bozkurt, A. (2021). Examination of the Hexad user types and their relationships with gender, game mode, and gamification experience in the context of open and distance learning. Online Learning, 25(4), 250-266. DOI:10.24059/olj.v25i4.2276 
Open and Distance Learning (ODL), and the flexible learning opportunities and support of life-long learning processes it engenders, has become part of mainstream education along with online content delivery methods, and continues to gain prevalence. The time-wise and/or placewise separation of the learner, instructor, and content in ODL, however, may cause the learner to feel devoid of interactions or social relationships (Kegeyan, 2016; Subramanian, 2016). It would be safe to argue that communication, interaction, and motivation are important components of ODL (Bozkurt, 2020). Hone and El Said (2016) claim that online learners tend to drop out of the system due to the poor interaction with instructors and other learners, insufficient feedback, and the lack of teamwork or group interactions. Accordingly, new suggestions may be needed on how to enhance learner-learner, learner-instructor, and learner-content interactions and how to improve the social and emotional statuses of learners in online environments, and so to increase success and satisfaction in ODL contexts. In this sense, gamification can be put forward as an answer to the questions of how to increase student motivation, how to improve course attendance, how to bolster the student experience (Pilkington, 2018), how to increase the social and cognitive interactions between the learner and the instructor (Abu-Dawood, 2016), and how to support learner autonomy (Kopcha, Ding, Neumann, \& Choi, 2016).

\section{Related Literature}

Gamification is the use of game design elements in non-game contexts (Deterding et al., 2011; Werbach, \& Hunter, 2012). Though they sound alike, gamification, game-based learning, and serious games are different concepts (Marczewski, 2015). The general drive behind the use of gamification in education is to utilize the positive design elements of video games with single player or multiplayer game mode options (i.e., reward, socialization, autonomy, risk-taking, experimentation and challenges) to improve learner motivation and learning in a learning environment (Kopcha et al., 2016) or in different settings. In other words, gamification is the adaptation of certain game mechanics, such as points, badges, and leaderboards, to learning environments to make learning more fun, attractive, and sustainable. According to the Octalysis Model, the gamification design model developed by Chou (2016), the common goal of successful games is to motivate people to exhibit desired behavior by targeting one or more of eight basic instincts (accomplishment, meaning, social influence, etc.) of the individual. There have been several previous studies supporting the utilization of gamification in educational processes (Bovermann, \& Bastiaens, 2018; Dicheva, Dichev, Agre, \& Angelova, 2015; Vaibhav, \& Gupta, 2014). Kapp (2012), and Werbach and Hunter (2012), however, have suggested that gamification may not be suitable for every system, in that it might not produce the same effect in every learning environment. As such, it would seem to be important to carefully analyze the systems that are planned to be gamified, to determine whether there is a need for gamification, and if so, to carefully carry out the gamification design. Werbach and Hunter (2012) have pointed out that identifying the users of the gamification is just as important as determining the targets, target behaviors, activity cycles, entertainment elements and proper tools for gamification design.

In a review of the literature, Bartle's (1996) player typology, as well as several other player typologies, are worthy of note (Nacke, Bateman, \& Mandryk, 2014; Ferro, Walz, \& Greuter, 2013). However, these typologies were created for game designs and, therefore, there is a need for new models specifically developed for gamified systems. To address this need, Marczewski (2015) classified gamification users under six user types based on the level of 
intrinsic or extrinsic motivations they have during the interaction with gamified systems (Figure 1). The six Hexad user types used in the present study are:

Socializers are motivated by being in contact with or establishing social relationships with others.

Free Spirits are motivated by autonomy and self-expression. They enjoy discovering and creating within a system.

Achievers are motivated by competence or specialization. They are open to learning new things and developing themselves and seek to overcome challenges during such processes.

Philanthropists are attracted by the purpose and meaning of the thing they are doing. Such people, who can be described as self-sacrificing, want to help others without any reward in return.

Players are motivated by external rewards (i.e., points, badges, leaderboards). They fulfill all the assignments asked of them to obtain the reward from the system.

Disruptors are motivated by change. They continuously force the system to change, either positively or negatively, by setting themselves or others to work.

Figure 1

The Gamification User Types Hexad (Marczewski, 2015)

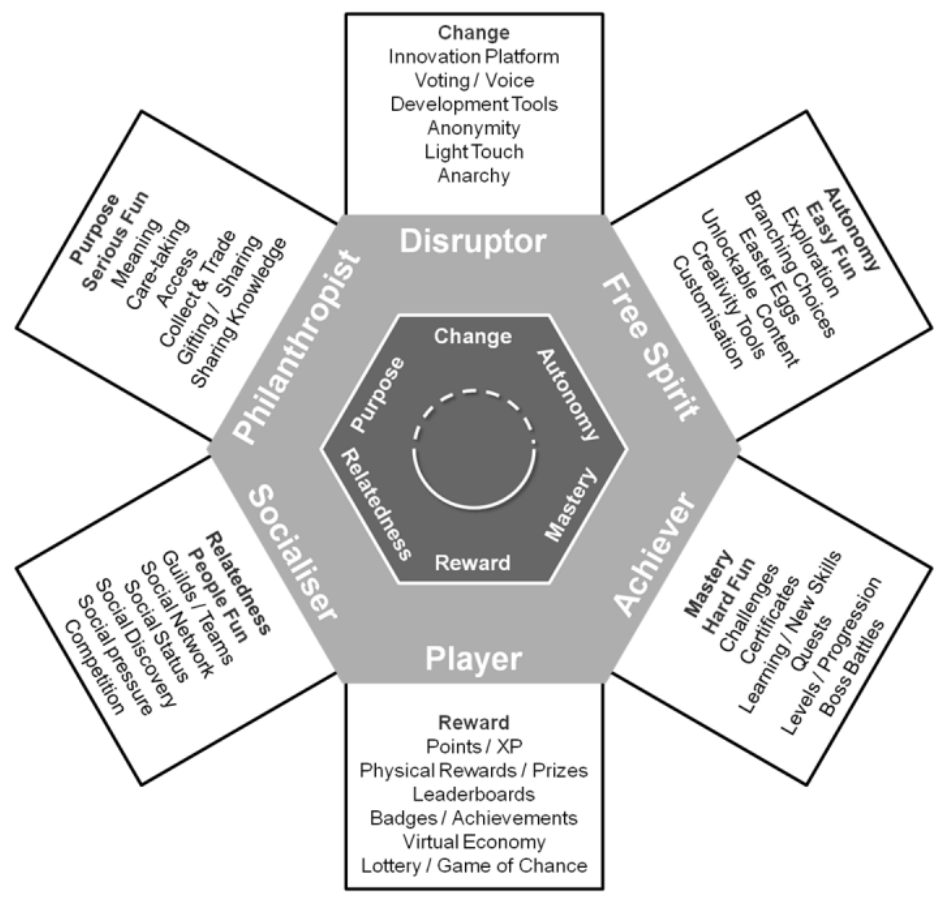


As is seen in Figure 1, Socializers, Free Spirits, Achievers, and Philanthropists are mostly motivated intrinsically, while Players are extrinsically motivated. In Self-Determination Theory (SDT), people with intrinsic motivation display an interest in the activity itself, and the resulting reward is the pleasure and happiness people get from the action (Ryan \& Deci, 2017). In extrinsic motivation, unlike intrinsic motivation, there is an external reward, social approval, or avoidance of punishment (Ryan \& Deci, 2000). As stated by Ryan and Deci (2000), autonomy, competence, and relatedness are the innate basic psychological needs of the individual. When these needs are met, people feel satisfied, which results in increased intrinsic motivation (Kapp, 2012). As the source of motivation for the intrinsically motivated user types (Free Spirits, Socializers, and Achievers) in the Gamification User Types Hexad, autonomy refers to the ability of people to guide their own behaviors; competence refers to the sense people have of their competence in learning and specializing in a subject; and relatedness refers to the feeling of being connected with others. Purpose (meaning), on the other hand, which supports the intrinsic motivation to fulfill challenging tasks (Davis et al., 2016), has been associated with the Philanthropist user type.

Previous studies (Mora et al., 2019; Tondello et al., 2016; Tondello et al., 2019) have identified the most common user types to be Philanthropists, Achievers, and Free Spirits, while Disruptors are less common. In a similar study by Fischer, Heinz, and Breitenstein (2018), Philanthropists, Free Spirits, and Socializers were found to be more common in the gamified learning management system than other user types.

When examining the different user types in the context of gender, women have been observed to score partially higher in the Philanthropists, Socializers, Free Spirits, and Achievers user types (i.e., intrinsic motivation) than men, whereas men's scores were slightly higher in Disruptor category than those of women (Tondello et al., 2019). Another study (Mora et al., 2019) reported women to be more commonly Philanthropists and Achievers, while men were more commonly Players and Disruptors.

The literature review also unearthed studies assessing the link between game mode and user types. Barata et al. (2014) investigated the association between gaming habits and learner performance in a gamified learning experience, looking into what kind of students could be observed and how their behaviors were related to their game preferences in a gamified environment. The authors used the Brainhex player type model, which includes an online questionnaire, to classify the learners according to their gameplay styles. Their findings suggested that the learners who corresponded most with the Disruptors in Marczewski's (2015) classification usually preferred single player game modes.

\section{Purpose of the Research}

Based on the above considerations, the overall purpose of the present study was to examine the user types and the variables with the potential to be associated with such types (gamification experience, game mode, and gender) in gamification within the context of ODL. It also aimed to discuss how the Hexad user types contribute to the gamification system and how gamified ODL systems can be developed to engage these six Hexad types. In accordance with this overall purpose, this study sought to answer the following question: Do the Hexad user types differ significantly in terms of gender, gamification experience, and preferred game mode? 


\section{Research Model and Design}

\section{Methodology}

In accordance with the purpose of the study, the research applied a cross-sectional survey design using a quantitative research methodology (Creswell, 2012). This study intends to examine ODL learners in terms of the gamification Hexad user types and considering that crosssectional survey design is useful to "examine current attitudes, beliefs, opinions, or practices" (Creswell, 2012, p. 405) on the basis of different variables, it is thought that the research design is a good fit for the overall aim of the study.

\section{Sample}

For the evaluation of gamification user types in terms of game mode, gamification experience, and gender in ODL environments, a study universe comprising 1,120,000 learners enrolled in the Anadolu University Open Education System, which provides mass education in this regard, were identified as of January 2019. The study involved 2,292 students enrolled in the Anadolu University Open Education System in the fall semester of 2018-2019 academic year, including 1,522 women and 770 men. The age of the study participants varied between 18 and 68. The gamification experience defined in the study was measured based on whether the students had made use of SoruKüp, a gamified web-based exercise application within the Anadolu University Learning Management System (LMS). Within the sample, and based on the collected data, the number of students who had tried the above-mentioned application was 434, while 1,858 students had not. The ethical approval was granted by Anadolu University Institutional Review Board (IRB).

\section{Data Collection and Analysis Procedures}

The Gamification User Types Hexad Scale developed by Tondello et al. (2016) was based on Marczewski's (2015) Hexad framework, which differs from other player classifications in its consideration of user types defined specifically for gamification. The statistical analyses in the study revealed that the scale was able to empirically measure Marczewski's user types (Tondello et al., 2016), which are also the subject of the present study. Accordingly, it is believed that the use of the Turkish adaptation (Akgün, \& Topal, 2018) of the original scale will contribute to improving Marczewski's user type classification. The adapted scale is a 7-point Likert-type scale consisting of 22 items.

Outlier calculations were made to ensure the normality assumption, and thus, the Mahalanobis distance (MD) was calculated. For this test, a tight statistical significance level of $\mathrm{p}$ $<.001$ is recommended (Kline, 2005), and as a result of the Mahalanobis distance analysis made in this context, 146 people who were calculated according to $\mathrm{p}<0.001$ and greater in regard to the Chi-square distribution table were excluded from the analysis. For normal distribution of data, kurtosis, and skewness, which both fell within the range between -2 and +2 were considered acceptable values (George \& Mallery, 2016; Tabachnick \& Fidell, 2007).

A confirmatory factor analysis (CFA) was carried out to confirm the Turkish version of the scale in the present study. Fit indices were calculated based on the CFA results, and the Chisquare value $\left(x^{2} / \mathrm{sd}=7,7, p=0.001, N=2292\right)$ was found to be significant and above the acceptable values $\left(x^{2} / \mathrm{sd}=3\right.$ and $\left.x^{2} / \mathrm{sd}=5\right)$ (Wheaton, Muthen, Alwin, \& Summers, 1977). As such, the second item from the Players subdimension, the first item from the Disruptors subdimension, the third item from the Achievers subdimension, and the third item from the Socializers subdimension were removed due to the poor fit with the scale. The repeated CFA showed that the Chi-square value was $\left(x^{2} / d f=4.9, p=0.001, N=2292\right)$ and within the acceptable values. Kline (2005) suggested in fact that the Chi-square value is sensitive to sample 
size, which leads to difficulties in establishing a certain Chi-square value alone for the model fit. Given the sample size of the present study $(n=2292)$, the Chi-square value seems acceptable (Wheaton et al., 1977). As is seen in Table 1, the fit indices are calculated based on the confirmatory factor analysis results and are at excellent acceptable levels.

Table 1

The Gamification User Types Hexad Scale CFA Fit Indices

\begin{tabular}{llll}
\hline CFA fit indices & Excellent fit indices & Acceptable indices & $\begin{array}{l}\text { Indices resulting from } \\
\text { the study }\end{array}$ \\
\hline $\mathrm{x}^{2} / \mathrm{sd}$ & $0 \leq \mathrm{x}^{2} / \mathrm{df} \leq 2$ & $2 \leq \mathrm{x}^{2} / \mathrm{df} \leq 5$ & 4.9 \\
$\mathrm{TLI}$ & $.95 \leq \mathrm{GFI} \leq 1.00$ & $.90 \leq \mathrm{GFI} \leq .95$ & .90 \\
$\mathrm{CFI}$ & $.95 \leq \mathrm{CFI} \leq 1.00$ & $.90 \leq \mathrm{CFI} \leq .95$ & .92 \\
$\mathrm{RMSEA}$ & $.00 \leq \mathrm{RMSEA} \leq .05$ & $.05 \leq \mathrm{RMSEA} \leq .08$ & .041 \\
SRMR & $.00 \leq \mathrm{SRMR} \leq .05$ & $.05 \leq \mathrm{SRMR} \leq .10$ & .03 \\
\hline
\end{tabular}

Table 2 presents the descriptive statistics and CFA factor loadings for the Turkish version of the Gamification User Types Hexad scale. The CFA revealed all statements to be significant and the factor loadings to be at acceptable levels (0.332-0.944). The reliability of the factors for the scale in Turkish was tested by calculating Cronbach's Alpha internal consistency coefficient, and the alpha coefficients were 0.64 for Philanthropists, 0.73 for Socializers, 0.60 for Free Spirits, 0.76 for Achievers, 0.79 for Disruptors and 0.86 for Players. Since the values obtained were above the threshold (cut-off) values, the factors were considered reliable (Hair et al., 2019). The basic statistical analysis of the study was conducted using the IBM SPSS Statistic 25 software package, and the confirmatory factor analysis was made using the R "Lavaan" package (Rosseel, 2012).

Table 2

Mean, Standard Deviation, Factor Loadings and Cronbach's Alpha Values of the Scale

\begin{tabular}{llllll}
\hline Factors & Items & $\underline{\boldsymbol{X}}$ & SD & $\begin{array}{l}\text { CFA Factor } \\
\text { Loading }\end{array}$ & Cronbach's $\underline{\boldsymbol{\alpha}}$ \\
\hline Philanthropists & P1 & 6.14 & 1.007 & 0.503 & 0.64 \\
& P2 & 5.74 & 1.467 & 0.450 & \\
Socializers & P3 & 6.55 & 0.672 & 0.405 & \\
& P4 & 6.15 & 0.970 & 0.533 & \\
Free Spirits & S2 & 6.12 & 1.118 & 0.520 & 0.73 \\
& S4 & 5.55 & 1.264 & 0.654 & \\
& F1 & 5.94 & 0.963 & 0.681 & 0.60 \\
Achievers & F2 & 6.09 & 1.019 & 0.512 & \\
& F3 & 6.12 & 1.098 & 0.348 & 0.76 \\
Fisruptors & A1 & 6.37 & 0.826 & 0.332 & \\
Players & A2 & 5.50 & 1.315 & 0.380 & \\
& A4 & 6.12 & 0.997 & 0.702 & 0.79
\end{tabular}




\section{Limitations}

Gamification is a recent research area, and this study is one of the earlier studies that examines gamification user types in a massive ODL environment. Though this can be considered as a strength of the study, the researchers acknowledge the following limitations: First, the data of the study is collected from one specific ODL system and different ODL systems with different learning designs can provide complementary findings. Second, gamification user types are related to social and psychological aspects, thus, different research that considers such variables can provide a broader understanding. Finally, learners' attitudes and practices that are related to their gamification user types can be affected by the cultural settings and a replication of this study in different cultural settings can lead to different research findings.

\section{Descriptive Statistics for the Hexad User Types}

\section{Findings}

Table 3 demonstrates the descriptive distributions of the variables related to Philanthropists, Socializers, Free Spirits, Achievers, Disruptors, and Players as the student user types. It is worth noting that the participants of the study may display the characteristics of different user types to varying degrees. Therefore, the overall distribution of the scores of each user type in the sample should be considered.

Table 3

Descriptive statistics for the Hexad gamification user types.

\begin{tabular}{llllll}
\hline Construct & $\underline{\mathbf{n}}$ & Min. & Max. & $\underline{\boldsymbol{X}}$ & $\boldsymbol{S D}$ \\
\hline $\begin{array}{l}\text { Philanthrop } \\
\text { ists }\end{array}$ & 2292 & 2.75 & 7.00 & 6.14 & 0.67 \\
Achievers & 2292 & 2.33 & 7.00 & 6.06 & 0.77 \\
Free Spirits & 2292 & 3.25 & 7.00 & 6.02 & 0.63 \\
Socializers & 2292 & 1.67 & 7.00 & 5.86 & 0.81 \\
Players & 2292 & 1.00 & 7.00 & 5.41 & 1.24 \\
Disruptors & 2292 & 1.00 & 7.00 & 3.42 & 1.45 \\
\hline
\end{tabular}

In the study, the most common user types are Philanthropists, Achievers, and Free Spirits, followed by Socializers and Players, while Disruptors are the least common user type in ODL environments within the scope of this study, and these findings parallel those of previous studies (Fischer et al., 2018; Mora et al., 2019; Tondello et al., 2016; Tondello et al., 2019;).

The study findings also support the principles of SDT, which is the basis for the user type classification developed specifically for gamification by Marczewski (2015). Our finding that Free Spirits, Achievers, and Philanthropists, which were associated with autonomy, competence, and meaning (purpose), respectively, were the most common user types, and that Socializers, associated with relatedness, followed the means of the other user types suggest that the basic psychological needs and the desire to fulfill such needs, as argued by SDT and mentioned also by Tondello et al. (2019), are also strong sources of motivation for the ODL systems designed to be gamified. Our findings, further, are in line with the ideas put forward in the Octalysis Model 
(Chou, 2016), which was developed within the context of gamification. Among the eight core motivations mentioned in the model, meaning can be associated with Philanthropists; development and accomplishment with Achievers; creativity with Free Spirits; and social influence and relatedness with Socializers. Therefore, such user types, being the most common in the present study, may lead to the idea that especially the core motivations associated with these user types should be considered in ODL environments.

Moreover, the finding of the above-mentioned studies (Tondello et al., 2019; Tondello et al., 2016), as well as the present study, that Players follow the other user types with the highest averages supports the idea that external rewards are one of the most important factors in promoting motivation, as expressed in SDT (Ryan \& Deci, 2000). This finding, however, should be discussed carefully. As also dwelled on in the overjustification effect (Lepper, Greene, \& Nisbett, 1973), if the Player user type focus on extrinsic rewards such as points, badges, and leaderboards more than the learning itself in gamified ODL systems, they may not maintain interest in learning activities in the absence of such rewards. Accordingly, this user type may be gradually integrated with intrinsically user types through a steady reduction of external rewards after they become accustomed to the system, internalize the goals and objectives, and give meaning to themselves, as mentioned also by Marczewski (2015). That said, further studies are needed to observe whether such a situation materializes.

When examining the above-stated distribution of user types in the context of this study and other related studies, it can be understood that Disruptors exhibit a unique distribution pattern (Mora et al., 2019; Tondello et al., 2016; Tondello et al., 2019). The lower mean in this user type, who are motivated by the triggering of change and acts with the drive to test the system limits, indicates that the motivation emerging out of the desire to instigate change should be taken into consideration in ODL environments, even though it is not as common as the other factors in terms of its effect on motivation.

The Killer type from Bartle's (1996) player typology, which demonstrates similarities with Disruptors, thrive on causing stress to other players or attacking other characters within the system. That said, a good game needs Killers, as balance is needed among the player types for a good game flow, even if the number of each individual type is not equal (Bartle, 1996). In other words, a lack of sufficient Killers in a game, and enough Disruptors in systems that have been gamified or are planned to be gamified may suggest that the system is not challenging enough, as Disruptors are also motivated by their ability to force the system into either positive or negative change, and by testing the system in a similar way to the Killers. For instance, it is believed that students who reveal system vulnerabilities, who always criticize the system, who provoke other users and who always try to break the rules in ODL environments, may more resemble this user type. This user type can thus be described as the naughty kids of gamified systems and is likely to cause an increased sense of excitement in gamified systems or cause other user types or system administrators to be permanently on the alert. In brief, all types of motivation, and thus Disruptors, are needed in the gamification of ODL environments to create a game effect in the system.

Orji, Tondello, and Nacke (2018) have stated that persuasive gameful systems are important in bringing about change in the behaviors of individuals by employing certain persuasive strategies and increasing system effectiveness through system personalization. Their study findings have shown that persuasive techniques such as competition, which addresses especially the Players, Socializers, and Disruptors, but do not adversely affect other user types; and cooperation, social comparison, and reward, which positively affect especially the Players 
and Socializers and do not adversely affect other user types, are needed if persuasive gamification systems are to reach large masses (Orji et al., 2018). It is, therefore, believed that using such mechanics as leaderboards, status, countdowns within social comparison; communal discovery and social fabric of games within cooperation; points, virtual goods, reward schedules, and physical rewards within reward (Orji et al., 2018) will have a positive impact on attracting the attention of a wider learner profile in ODL environments.

\section{Evaluation of User Types based on Gender, Gamification Experience, and Game Mode among ODL Students}

An Independent Samples T-Test was used to establish whether there was a difference in user types by gender, gamification experience and preferred game mode. When the user types were analyzed in terms of gender, gamification experience and game mode, the Levene's test found a homogenous distribution in all variables $(p>0.05)$, and 'equal variances assumed' was used to interpret the analysis results. The obtained results are presented in Table 4 for gender, Table 5 for game mode, and Table 6 for gamification experience.

Table 4

Examination of User Types in the Context of Gender

\begin{tabular}{|c|c|c|c|c|c|c|}
\hline Constructs & Gender & $\underline{\mathbf{n}}$ & $\underline{x}$ & $S D$ & $\underline{t}$ & $d f$ \\
\hline \multirow{2}{*}{ Philanthropists } & Male & 770 & 6.15 & 0.70 & \multirow{2}{*}{0.336} & \multirow{2}{*}{2290} \\
\hline & Female & 1522 & 6.14 & 0.66 & & \\
\hline \multirow{2}{*}{ Socializers } & Male & 770 & 5.90 & 0.81 & \multirow{2}{*}{1.180} & \multirow{2}{*}{2290} \\
\hline & Female & 1522 & 5.86 & 0.81 & & \\
\hline \multirow{2}{*}{ Free Spirits } & Male & 770 & 6.05 & 0.64 & \multirow{2}{*}{1.391} & \multirow{2}{*}{2290} \\
\hline & Female & 1522 & 6.01 & 0.64 & & \\
\hline \multirow{2}{*}{ Achievers } & Male & 770 & 6.07 & 0.80 & \multirow{2}{*}{0.014} & \multirow{2}{*}{2290} \\
\hline & Female & 1522 & 6.07 & 0.76 & & \\
\hline \multirow{2}{*}{ Disruptors } & Male & 770 & 1.29 & 1.48 & \multirow{2}{*}{$3.005 * *$} & \multirow{2}{*}{2289} \\
\hline & Female & 1522 & 3.48 & 1.43 & & \\
\hline \multirow{2}{*}{ Players } & Male & 770 & 5.46 & 1.26 & \multirow{2}{*}{1.093} & \multirow{2}{*}{2290} \\
\hline & Female & 1522 & 5.40 & 1.24 & & \\
\hline
\end{tabular}

**p $<0.01 ;(1-$ Strongly Disagree; 7-Strongly Agree $)$.

Table 4 shows that user types varied significantly by gender only for the Disruptors factor ( $t$ : 3.005; df: 2289; $p<0.01)$. There was no significant difference in the other factors $(p>0.05)$.

Based on the above-stated findings, women were observed to be more likely to be Disruptors than men in ODL environments, although men were found to be more likely to be Disruptors in other studies (Fischer et al., 2018; Tondello et al., 2019). This may be due to the sociocultural differences of the contexts in which the studies were conducted.

The significant difference in the Disruptors user type in favor of women indicates that women are more likely to be motivated by the triggering of change in ODL environments. Such a desire for change may manifest in the form of challenges to others, the system, or the system 
administrators, and testing the limits of the existing system, but can also be interpreted as an effort to further improve the system. Hunicke, LeBlanc, and Zubek (2004) emphasized several mechanical, dynamic and esthetic factors that make games successful; while Zichermann and Cunningham (2011) stated that especially the use of proper mechanics may result in terminal reactions in individuals. Such findings reveal once again that it is important to shift the desire for change in the existing Disruptors user type toward the positive, and to use proper gamification mechanics in the systems planned to be gamified for this purpose.

Table 5

Examination of user types in the context of preferred game mode

\begin{tabular}{|c|c|c|c|c|c|c|}
\hline Constructs & Game Mode & $\underline{\mathbf{n}}$ & $\underline{x}$ & $S D$ & $\underline{t}$ & $d f$ \\
\hline \multirow{2}{*}{ Philanthropists } & Multiplayer & 956 & 6.18 & 0.66 & \multirow{2}{*}{ 2.035* } & \multirow{2}{*}{2290} \\
\hline & Single Player & 1336 & 6.12 & 0.68 & & \\
\hline \multirow{2}{*}{ Socializers } & Multiplayer & 956 & 5.97 & 0.78 & \multirow{2}{*}{$5.241 * * *$} & \multirow{2}{*}{2290} \\
\hline & Single Player & 1336 & 5.79 & 0.83 & & \\
\hline \multirow{2}{*}{ Free Spirits } & Multiplayer & 956 & 6.04 & 0.63 & \multirow{2}{*}{0.975} & \multirow{2}{*}{2290} \\
\hline & Single Player & 1336 & 6.01 & 0.65 & & \\
\hline \multirow{2}{*}{ Achievers } & Multiplayer & 956 & 6.14 & 0.76 & \multirow{2}{*}{$3.478 * *$} & \multirow{2}{*}{2290} \\
\hline & Single Player & 1336 & 6.02 & 0.78 & & \\
\hline \multirow{2}{*}{ Disruptors } & Multiplayer & 956 & 3.47 & 1.48 & \multirow{2}{*}{1.368} & \multirow{2}{*}{2289} \\
\hline & Single Player & 1336 & 3.39 & 1.43 & & \\
\hline \multirow{2}{*}{ Players } & Multiplayer & 956 & 5.57 & 1.21 & \multirow{2}{*}{$5.016 * * *$} & \multirow{2}{*}{2290} \\
\hline & Single Player & 1336 & 5.31 & 1.26 & & \\
\hline
\end{tabular}

Table 5 shows that Philanthropists ( $t: 2.035$; df: 2290; $p<0.01)$, Socializers $(t: 5.241 ;$ df: $2290 ; p$ $<0.01)$, Achievers ( $t: 3.478$; df: 2290; $p<0.01)$ and Players $(t: 5.016$; df: 2290; $p<0.01)$ differed significantly in terms of preferred game mode, while there was no significant difference for Free Spirits or Disruptors $(p>0.05)$. In other words, the multiplayer game mode was preferred more by Philanthropists, Socializers, Achievers, and Players than the single-player game mode. The findings of our research partially concur with those of a study (Barata et al., 2014) in which all students types, other than the one whose player profile corresponded most to Disruptors preferred the multiplayer game mode.

The preference for multiplayer game modes among these user types suggests that this mode may be more suited to the nature of certain user types. For instance, it is possible that the multiplayer game mode is preferred by Achievers as they want to see themselves as more competent than others; by Socializers to be in contact with others socially; by Philanthropists to help others in the game; and by Players to battle with others for the rewards. It is a known fact that digital game preferences are affected by social and cultural conditions (Pala \& Erdem, 2011) such as gaming with familiar or unfamiliar people, whether the game is recognized in the culture, habits, and popular activities of the period (Engl, \& Nacke, 2013). It is, thus, believed that the preference for the multiplayer game mode in four user types in the present study may be 
attributable to sociocultural conditions. Such preferences in learners are believed to be a result of the collectivist culture that is characterized by solidarity, sharing and cohesion with others (Hofstede, 2001). Nevertheless, further studies are needed to demonstrate whether this is due to the above-mentioned reasons.

It is believed that the influence of Socializers and Philanthropists, who are motivated by being in contact with others, but for different purposes, i.e., those who prefer playing multiplayer games in which there is engagement with others, and where there is cooperation and competition, should be taken into consideration in ODL environments. It is thereby believed that the first step of the Flow experience (Csikszentmihalyi, 1991) can be realized in gamification systems by ensuring that individuals who prefer different game modes or different user types are able to set their own goals; in other words, making users feel a sense of control.

Table 6

Examination of user types in the context of gamification experience

\begin{tabular}{|c|c|c|c|c|c|c|}
\hline Constructs & Gamification Experience & $\underline{\mathbf{n}}$ & $\underline{x}$ & $S D$ & $\underline{t}$ & $d f$ \\
\hline \multirow{2}{*}{ Philanthropists } & No & 1858 & 6.15 & 0.68 & \multirow{2}{*}{0.777} & \multirow{2}{*}{2290} \\
\hline & Yes & 434 & 6.12 & 0.68 & & \\
\hline \multirow{2}{*}{ Socializers } & No & 1858 & 5.87 & 0.81 & \multirow{2}{*}{0.095} & \multirow{2}{*}{2290} \\
\hline & Yes & 434 & 5.87 & 0.80 & & \\
\hline \multirow{2}{*}{ Free Spirits } & No & 1858 & 6.00 & 0.64 & \multirow{2}{*}{$-3.836 * * *$} & \multirow{2}{*}{2290} \\
\hline & Yes & 434 & 6.13 & 0.62 & & \\
\hline \multirow{2}{*}{ Achievers } & No & 1858 & 6.07 & 0.77 & \multirow{2}{*}{-0.199} & \multirow{2}{*}{2290} \\
\hline & Yes & 434 & 6.08 & 0.80 & & \\
\hline \multirow{2}{*}{ Disruptors } & No & 1858 & 3.44 & 1.44 & \multirow{2}{*}{1.338} & \multirow{2}{*}{2289} \\
\hline & Yes & 434 & 3.34 & 1.49 & & \\
\hline \multirow{2}{*}{ Players } & No & 1858 & 5.38 & 1.26 & \multirow{2}{*}{$-2.789 * *$} & \multirow{2}{*}{2290} \\
\hline & Yes & 434 & 5.57 & 1.18 & & \\
\hline
\end{tabular}

***p $<0.001 ; * * p<0.01 ;(1-$ Strongly Disagree; 7-Strongly Agree).

Table 6 shows that Free Spirits $(t:-3.836$; df: $2290 ; p<0.01)$ and Players $(t:-2.789 ;$ df: $2290 ; p$ $<0.01)$ are significantly different in terms of gamification experience. No significant difference was established for the other user types $(p>0.05)$.

Within the scope of the study, gamification experience was measured based on whether the learners had made use of the SoruKüp application, which is a web-based exercise application involving gamification elements in the Anadolum LMS. It was found that learners of the Free Spirit and Player user types seemed more experienced in this application in the ODL environment. Several previous studies (Krath \& von Korflesch, 2021; Lopez \& Tucker, 2019; Marczewski, 2015; Orji, Nacke, \& Di Marco, 2017; Tondello et al., 2016) have investigated which game mechanics are best suited to the motivation of each user type in gamification. The findings of the present study indicate that the gamification mechanics, such as points, leaderboards, and badges, used in the gamified SoruKüp application may appeal more to Players, while the opportunity to add to the questions provided to the learners by the application may appeal to the Free Spirits. Yet, the question of whether such game mechanics affect other user 
types sufficiently comes to mind, since there was no statistically significant difference in the gamification experience of the other user types. As such, further studies are required to investigate which gamification mechanics motivate other user types and to observe the extent to which they are effective.

\section{Conclusion and Recommendations}

The present study has investigated the six Hexad gamification user types and their relationships with gender, preferred game mode, and gamification experience. Based on the study findings, and the Gamification User Types Hexad Scale, the most common user types were found to be Philanthropists, Achievers, and Free Spirits in ODL environments, followed by Socializers and Players with lower means, and then by Disruptors with the lowest mean. Women were observed to be more likely to be Disruptors than men. There was a significant difference in the preference for multiplayer game modes among Philanthropists, Socializers, Achievers, and Players. Free Spirits and Players seemed to be more experienced in the SoruKüp application, which contains gamification elements.

Based on research findings, the following suggestions can be made for future research directions and gamified ODL environments:

Efforts should be made to examine which gamification mechanics attract which user types, or are useful or not for which user types in gamification applications, and making improvements to applications accordingly; researchers should consider the core drives such as meaning, development, accomplishment, creativity, social influence and relatedness, which are associated especially with the common user types (Philanthropists, Achievers, Free Spirits, Socializers) when gamification is used in ODL environments; researcher should examine whether Players shift to intrinsically-motivated user types, as suggested in literature, when external rewards such as the points, badges, and leaderboards that motivate them are gradually decreased after the users internalize and give meaning to the goals and objectives of the system; the industry should consider gamification elements that will also motivate Disruptors in an educational context when designing gamification systems; the industry should allow Disruptors to become more autonomous by enabling personal changes to be made to certain gamification applications in order to ensure their motivation sources are directed toward a positive direction in ODL environments, based on the understanding that they act with a desire to challenge the limits of the system and so bring about change; and practitioners should use personalized gamification applications in ODL environments when considering the game mode preferences and motivational sources that can be associated with gamification.

\section{Acknowledgements}

This study is the improved version of the master thesis entitled, "The examination of gamification user types, motivation and academic achievement in open and distance learning", completed in the Distance Education Department of the Social Sciences Institute at Anadolu University in 2019.

A part of the thesis was also presented at $12^{\text {th }}$ International Conference of Education, Research, and Innovation (ICERI2019) and published in proceedings as a study entitled, "Distribution of Hexad gamification user types and their association with intrinsic motivation in open and distance learning systems." 


\section{Declarations}

The author declared no potential conflicts of interest with respect to the research, authorship, and/or publication of this article.

The author received approval from the research ethics review board of Anadolu University, Turkey for this study.

The author received no financial support for the research, authorship, and/or publication of this article. 


\section{References}

Abu-Dawood, S. (2016, July). The cognitive and social motivational affordances of gamification in e-learning environment. In 2016 IEEE 16th International Conference on Advanced Learning Technologies (ICALT) (pp. 373-375). Austin, TX, United States. https://doi.org/10.1109/icalt.2016.126

Akgün, Ö. E., \& Topal, M. (2018). Adaptation of the gamification user types hexad scale into Turkish. International Journal, 5(3), 389-402. https://doi.org/10.21449/ijate.379139

Barata, G., Gama, S., Jorge, J. A., \& Gonçalves, D. J. (2014). Relating gaming habits with student performance in a gamified learning experience. Proceedings of the first ACM SIGCHI annual symposium on Computer-human interaction in play (pp. 17-25). Toronto, Canada. https://doi.org/10.1145/2658537.2658692

Bartle, R. (1996). Hearts, clubs, diamonds, spades: Players who suit MUDs. Journal of MUD research, 1(1), 19.

Bozkurt, A. (2020). Communication, interaction, and motivation: Following the theoretical footprints of distance education. Proceedings of Digital Education: 21st Century (pp. 29-31). Moscow, Russia.

Bovermann, K., \& Bastiaens, T. (2018, June). Using gamification to foster intrinsic motivation and collaborative learning: A comparative testing. - Proceedings of EdMedia + Innovate Learning (pp. 1128-1137). Amsterdam, Netherlands: Association for the Advancement of Computing in Education (AACE).

Chou, Y. K. (2016). Actionable gamification: Beyond points, badges, and leaderboards. Octalysis Media.

Creswell, J. W. (2012). Educational research: Planning, conducting, and evaluating quantitative and qualitative research. Pearson.

Csikszentmihalyi, M. (1991). Flow: The Psychology of Optimal Experience. Harper Perennial.

Davis, W. E., Kelley, N. J., Kim, J., Tang, D., \& Hicks, J. A. (2016). Motivating the academic mind: High-level construal of academic goals enhances goal meaningfulness, motivation, and self-concordance. Motivation and Emotion, 40(2), 193-202. https://doi.org/10.1007/s11031-015$\underline{9522-\mathrm{X}}$

Deterding, S., Dixon, D., Khaled, R., \& Nacke, L. (2011). From game design elements to gamefulness: Defining gamification. Proceedings of 15th International Academic MindTrek Conference: Envisioning Future Media Environments (-pp. 9-15). Tampere, Finland. https://doi.org/10.1145/2181037.2181040 
Dicheva, D., Dichev, C., Agre, G., \& Angelova, G. (2015). Gamification in education: A systematic mapping study. Journal of Educational Technology \& Society, 18(3), 1-14. https://www.jstor.org/stable/jeductechsoci.18.3.75

Engl, S., \& Nacke, L. E. (2013). Contextual influences on mobile player experience-A game user experience model. Entertainment Computing, 4(1), 83-91. https://doi.org/10.1016/j.entcom.2012.06.001

Ferro, L. S., Walz, S. P., \& Greuter, S. (2013, September). Towards personalised, gamified systems: an investigation into game design, personality and player typologies. Proceedings of the 9th Australasian Conference on Interactive Entertainment: Matters of Life and Death (p. 7). Melbourne, Australia. https://doi.org/10.1145/2513002.2513024

Fischer, H., Heinz, M., \& Breitenstein, M. (2018). Gamification of learning management systems and user types in higher education. In ECGBL 2018 12th European Conference on Game-Based Learning (pp. 91). Sophia Antipolis, France.

George, D., \& Mallery, P. (2016). IBM SPSS Statistics 23 step by step: A simple guide and reference. Routledge.

Hair, J. F., Black, W. C., Babin, B. J., \& Anderson, R. E. (2019). Multivariate data analysis. Cengage. https://doi.org/10.1007/978-3-642-04898-2_395

Hone, K. S., \& El Said, G. R. (2016). Exploring the factors affecting MOOC retention: A survey study. Computers \& Education, 98, 157-168. https://doi.org/10.1016/j.compedu.2016.03.016

Hunicke, R., LeBlanc, M., \& Zubek, R. (2004). MDA: A formal approach to game design and game research. Proceedings of the AAAI Workshop on Challenges in Game AI, 4(1), 1722-1726. California, United States. https://users.cs.northwestern.edu/ hunicke/MDA.pdf

Hofstede, G. (2001). Culture's consequences: Comparing values, behaviors, institutions, and organizations across nations (2nd ed.). Sage Publications.

Kapp, K. M. (2012). The gamification of learning and instruction: game-based methods and strategies for training and education. John Wiley and Sons.

Kegeyan, S. E. (2016). Distance learning: Its advantages and disadvantages. International Journal of Professional Science, 1, 71-75. https://cyberleninka.ru/article/n/distance-learning-itsadvantages-and-disadvantages

Kline, R. B. (2005). Principles and practice of structural equation modeling (2nd ed.). Guilford Publications.

Kopcha, T. J., Ding, L., Neumann, K. L., \& Choi, I. (2016). Teaching technology integration to K-12 educators: A 'Gamified' approach. TechTrends, 60(1), 62-69.

https://doi.org/10.1007/s11528-015-0018-z 
Krath, J., \& von Korflesch, H. F. (2021). Player types and game element preferences:

Investigating the relationship with the gamification user types HEXAD scale. International Conference on Human Computer Interaction (pp. 219-238). Online Conference. https://doi.org/10.1007/978-3-030-77277-2_18

Lepper, M. R., Greene, D., \& Nisbett, R. E. (1973). Undermining children's intrinsic interest with extrinsic reward: A test of the "overjustification" hypothesis. Journal of Personality and Social Psychology, 28(1), 129-137. https://doi.org/10.1037/h0035519

Lopez, C. E., \& Tucker, C. S. (2019). The effects of player type on performance: A gamification case study. Computers in Human Behavior, 91, 333-345.

https://doi.org/10.1016/j.chb.2018.10.005

Marczewski, A. (2015). Even ninja monkeys like to play: Gamification, game thinking and motivational design. CreateSpace Independent Publishing Platform.

Mora, A., Tondello, G. F., Calvet, L., González, C., Arnedo-Moreno, J., \& Nacke, L. E. (2019, June). The quest for a better tailoring of gameful design: An analysis of player type preferences. Proceedings of the XX International Conference on Human Computer Interaction (pp. 1-8). Donostia, Gipuzkoa, Spain. https://doi.org/10.1145/3335595.3335625

Nacke, L. E., Bateman, C., \& Mandryk, R. L. (2014). BrainHex: A neurobiological gamer typology survey. Entertainment Computing, 5(1), 55- 62.

https://doi.org/10.1016/j.entcom.2013.06.002

Orji, R., Nacke, L. E., \& Di Marco, C. (2017, May). Towards personality-driven persuasive health games and gamified systems. Proceedings of the 2017 CHI Conference on Human Factors in Computing Systems (pp. 1015-1027). Denver, Colorado, United States.

Orji, R., Tondello, G. F., \& Nacke, L. E. (2018). Personalizing persuasive strategies in gameful systems to gamification user types. Proceedings of the 2018 CHI Conference on Human Factors in Computing Systems (pp. 1-14). Montreal, Quebec, Canada.

https://doi.org/10.1145/3173574.3174009

Pala, F. K., \& Erdem, M. (2011). Dijital oyun tercihi ve oyun tercih nedeni ile cinsiyet, sınıf düzeyi ve öğrenme stili arasındaki ilişkiler üzerine bir çalışma [A study on the relationships between digital game preference and game preference reason with gender, class level and learning styles]. Ahi Evran Üniversitesi Kırşehir Eğitim Fakültesi Dergisi, 12(2), 53-71. https://dergipark.org.tr/en/pub/kefad/issue/59495/855160

Pilkington, C. (2018). A playful approach to fostering motivation in a distance education computer programming course: Behaviour change and student perceptions. International Review of Research in Open and Distributed Learning, 19(3). https://doi.org/10.19173/irrodl.v19i3.3664 
Rosseel, Y. (2012). lavaan: An R package for structural equation. Journal of Statistical Software, 48(2), 1-36 https://doi.org/10.18637/jss.v048.i02

Ryan, R. M., \& Deci, E. L. (2000). Darker and brighter sides of human existence: Basic psychological needs as a unifying concept. Psychological Inquiry, 11(4), 319338. https://doi.org/10.1207/s15327965pli1104_03

Ryan, R. M., \& Deci, E. L. (2017). Self-determination theory: Basic psychological needs in motivation, development, and wellness. Guilford Publishing.

Subramanian, R. M. (2016). The role of e-learning, the advantages and disadvantages of its adoption in Higher Education. HINDCO Publications.

Tabachnick, B. G., \& Fidell, L. S. (2007). Using multivariate statistics (5th ed.). Pearson.

Tondello, G. F., Mora, A., Marczewski, A., \& Nacke, L. E. (2019). Empirical validation of the gamification user types hexad scale in English and Spanish. International Journal of HumanComputer Studies. https://doi.org/10.1016/j.ijhcs.2018.10.002

Tondello, G. F., Wehbe, R. R., Diamond, L., Busch, M., Marczewski, A., \& Nacke, L. E. (2016, October). The gamification user types hexad scale. Proceedings of the 2016 annual symposium on computer-human interaction in play (pp. 229-243). Austin, Texas, United States. https://doi.org/10.1145/2967934.2968082

Vaibhav, A., \& Gupta, P. (2014, December). Gamification of MOOCs for increasing user engagement. 2014 IEEE International Conference on MOOC, Innovation and Technology in Education (MITE) (pp. 290-295). Patiala, India. https://doi.org/10.1109/mite.2014.7020290

Werbach, K., \& Hunter, D. (2012). For the win: How game thinking can revolutionize your business. Wharton Digital Press.

Wheaton, B., Muthen, B., Alwin, D. F., \& Summers, G. F. (1977). Assessing reliability and stability in panel models. Sociological Methodology, 8, 84-136. https://doi.org/10.2307/270754

Zichermann, G., \& Cunningham, C. (2011). Gamification by design: Implementing game mechanics in web and mobile apps. O'Reilly Media, Inc. 